\title{
Kdr Resistance Gene and Spatial Distribution of Anopheles gambiae Complex Members in a Secondary City in Central Africa: Ayos Case (South Cameroon)
}

\author{
Nopowo NT, Akono PN, Ngaha R, Offono LE, \\ Kojom R, Mache PN, Ngo Hondt OE, Mbida \\ Mbida JA and Mbongue RS* \\ Department of Animal Biology, Faculty of Science, \\ University of Douala, Cameroon \\ *Corresponding author: Mbongue RS, Department of \\ Animal Biology, Faculty of Science, University of Douala, \\ P.O. Box 24157 Douala, Cameroon
}

Received: August 24, 2021; Accepted: September 27, 2021; Published: October 04, 2021

\begin{abstract}
The study was conducted in December 2019 and February 2020 in two areas of Ayos city, Akoun (urban site) and Ebabodo (peri-urban site), in order to study the spatial distribution of members of the Anopheles gambiae complex, to determine their resistance status and to investigate the occurrence and distribution of the Kdr mutation. Mosquitoes were collected at the larval stage using the dipping method and then reared to the adult stage. The susceptibility of adult populations of An. gambiae s.I. to DDT and pyrethroids was assessed according to the WHO recommended protocol. Mosquitoes from the tests were identified by SINE PCR. Only test survivors were used for Kdr mutation testing by PCR. In the study sites, the gambiae complex was composed of An. coluzzii and An. gambiae living in sympatry in their oviposition sites with a predominance of An. coluzzii in Akoun (90.83\%) and Ebabodo (76.69\%). Tests with deltamethrin, permethrin and DDT revealed mortality rates of less than $70 \%$ whatever the locality of origin of the anopheles. Diagnostic PCR for the Kdr mutation showed that $100 \%$ of the survivors had the mutation in both sites, with frequencies of the resistant allele of 1.0 in both species.
\end{abstract}

The high resistance of $A n$. coluzzii and An. gambiae to insecticides requires the development of new insecticidal molecules.

Keywords: Anopheles coluzzii, An. gambiae, insecticides, Kdr mutation, Akoun, Ebabodo, Ayos, Cameroon, Central Africa

\section{Abbreviations}

DNA: Deoxyribonucleic Acid; CTAB: Cetyl Trimetyl Ammonium Bromide; DDT: Dichloro-Diphenyl-Trichloroethane; Kdr: Knock down resistance; MINSANTE: Ministère de la Santé Publique; OCEAC: Organization de Coordination pour la lutte contre les Endémies en Afrique Centrale; WHO: World Health Organization; PCR: Polymerase Chain Reaction; PNLP: Programme National de lutte contre le paludisme; LLINs: Long Lasting Insecticidal Nets; TKd: Time of Knock down; DDT: Dichlorodipheniltrichloroethane; RR: Resistant; SS: Sensitive

\section{Background}

Of all mosquito-borne diseases, malaria remains one of the most dangerous [1]. According to WHO statistics, malaria is responsible for 405,000 deaths per year worldwide, $95 \%$ of which occur in subSaharan Africa, where the disease is a major public health problem [2]. Children under 5 years of age, pregnant women and non-immune travelers are the groups most at risk [3].

In the absence of an operational vaccine, vector control remains the primary means of preventing and reducing malaria transmission $[3,4]$. This control is largely based on the use of insecticides for net impregnation or indoor residual spraying. Cameroon has included the insecticide-treated net in its national strategic plan for malaria control. Tens of millions of free mosquito nets have been distributed to the population throughout the country during free campaigns conducted by the government, with the peak of distribution in 2011, 2016 and more recently in 2019 [5,6]. However, several studies have revealed the resistance of malaria vectors to insecticides used in public health in Cameroon, particularly in the North [7], Littoral [8] and Centre [9] regions, thereby calling into consideration the bioefficacy of the mosquito nets currently used. One of the solutions to this resistance phenomenon is to control the resistance mechanisms developed by mosquitoes and their spatial distribution in a specific locality in order to ensure a more efficient vector control strategy. In Central Africa, the resistance mechanisms developed by members of the gambiae complex are reflected either by an increase in the activity of detoxification enzymes (metabolic resistance) or by the presence of L1014F and L1014S mutations involved in knockdown resistance [10]. Furthermore, some studies have shown that An. coluzzii is better adapted to the ecological conditions of urban environments, in opposition to An. gambiae which prefers peripheral sites [11,12]. Such information, which is important in the guidance of vector control strategies, is unfortunately only available in some large cities in Central Africa [13,14]. The resistance pattern of malaria vectors is unknown till date in the vast majority of secondary cities in this part of our continent. However, for the past few decades, these cities have become the main agricultural production basins, following the decline in agricultural activities observed in recent years in the large cities, which would be inherent to the anarchic occupation of cultivable land in relation to an ever-increasing demography. In the secondary cities, farmers lacking training are known for their uncontrolled use 


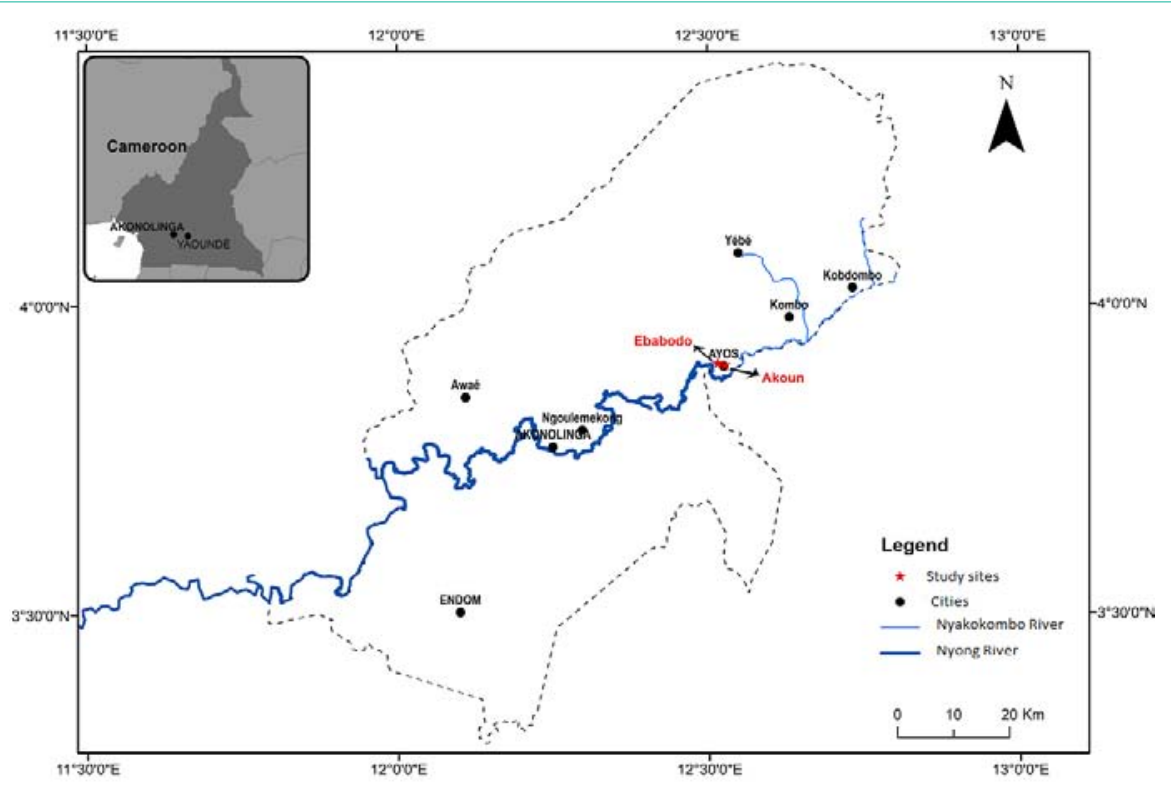

Figure 1: Studies sites location.

of pesticides, coupled with poor control of the frequency of their application in the plantations. This in addition to the widespread use of LLINs, contributes to the selection of pyrethroid-resistant strains.

Ayos is a secondary town in the southern Cameroon forest block, located $160 \mathrm{~km}$ east of Yaoundé (the political capital). As the main production area for cash crops such as cocoa and coffee, farmers use pesticides in an uncontrolled manner in order to boost production. The town also benefited from mass distribution of LLINs in 2011, 2016 and 2019. Unfortunately, since then, no data on insecticide resistance in malaria vectors and the resistance mechanisms involved are available. However, according to studies conducted by Akono et al. [15], malaria is endemic and its transmission is essentially ensured by An. gambiae s.l., whose larvae preferentially live on the banks of the Nyong River, which crosses the city from East to West.

The present study, whose aim is to complete the information on the resistance profile of Anopheles in the secondary cities of Central Africa, reviews the distribution of members of the An. gambiae complex, their resistance to insecticides and the distribution of the $\mathrm{Kdr}$ mutation in two peri-urban (Ebabodo) and urban (Akoun) neighbourhoods of the Ayos city.

\section{Methodology}

\section{Study site}

The study was conducted in Ayos ( $\left.03^{\circ} 54^{\prime} \mathrm{N} ; 1^{\circ} 31^{\prime} \mathrm{E}\right)$, a locality located $160 \mathrm{~km}$ east of the city of Yaoundé, the capital of Cameroon (Figure 1). The climate in equatorial Guinean has four seasons, two rainy (September to November and March to June) and two dry (December to February and July to August). The vegetation was originally forest but has been damaged by human activity. The hydrographic network is abundant, consisting of numerous rivers that flow into the River Nyong. The average annual rainfall was $1971.2 \mathrm{~mm}$ in 2010 . The average annual temperature was $25.53^{\circ} \mathrm{C}$ and the relative humidity was $80 \%$. The population, estimated at 14,950 , lives from agriculture, livestock and fishing. The inhabitants regularly use insecticides and pesticides to control the insects that carry diseases to animals, humans and plants. The rate of coverage of the city with LLINs was around $90 \%$. The use of LLINs, insecticides and pesticides can cause resistance in the mosquito vectors. The vast majority of residents go to the Ayos Regional Hospital as soon as they experience symptoms of fever.

\section{Larvae collection at Akoun and Ebabodo}

Akoun ( $3^{\circ} 54^{\prime} 102 \mathrm{~N} ; 12^{\circ} 31^{\prime}$ 054E) (Figure 1) is an urban site located in downtown Ayos in the background of the municipal market site. The houses are of modern type with walls made of breeze blocks and roofs of corrugated sheets. The population is cosmopolitan, consisting of students, traders, civil servants etc. This district is characterized by its rather high degree of unsanitary conditions, which are marked by the presence of rubbish bins littering its streets and alleys. In the rainy season, some abandoned containers and used tyres provide potential breeding grounds for Aedes. Nevertheless, some potholes and other clear, vegetated and sunny water points are also visible and would constitute anopheles breeding sites.

Ebabodo ( $3^{\circ} 54^{\prime} 295 \mathrm{~N} ; 1^{\circ} 31^{\prime}$ 631E) (Figure 1) is a barely anthropised site, located a few hundred metres from the Nyong River. The houses are of the traditional type, with walls made mostly of mud. The majority of the population is indigenous. The landscape is natural and dominated by vegetation whose regular plant species belong to the Gramineae and Piperaceae families. The population is at risk of mosquito bites due to the proximity of their homes to the River Nyong.

\section{Mosquito collection and treatment}

The Anopheles populations for testing were collected in the larval stage from natural sites (sewers, gutters, barrels, pits, cesspools and truck tyre tracks, puddles) using the dipping method [16]. Collection took place in December 2019 and February 2020, on five consecutive days per month, simultaneously in the Akoun and Ebabodo districts. The collected Anopheles larvae were reared in water from the breeding 
sites and fed with Tetrababy fish food [17]. The adults obtained were morphologically identified [18,19] and the adult females of $A n$. gambiae s.l. were exposed to insecticide tests.

\section{Insecticide sensitivity tests}

Insecticide sensitivity testing was carried out using 2-4 day old adult females of An. gambiae s.l., obtained from the rearing of fieldcollected larvae. The sensitive reference strain (Kisumu strain) bred at OCEAC was used to test the suitability of the impregnated papers. The procedure was in accordance with that recommended by the WHO [20]. The parameters monitored were knockdown time or the time required to knock out 50\% (tkd50) and 95\% (tkd95) of mosquitoes after an hour's contact with an insecticide of lethal concentration for a susceptible strain, and mortality after 24 hours of observation. The following concentrations were tested: DDT $4 \%$, permethrin $0.75 \%$ and deltamethrin $0.05 \%$. In the exposed tubes, knocked out mosquitoes were scored at regular 5 minutes intervals for 60 minutes. The anopheles were placed again on observation tubes and fed with $10 \%$ glucose solution and mortality was recorded after 24 hours of observation. Tests using untreated paper were used as controls. Mortality rates were corrected when controls were between 5 and 20\% [21]. The resistance and susceptibility status of the tested mosquitoes was assessed according to the following criteria: mortality rate $(<90 \%)$ $=$ resistant population; $(90 \%$ to $98 \%)=$ probable resistance; $(>98 \%)=$ susceptible population. Mosquitoes from the susceptibility tests were divided into three batches (susceptible/resistant/control) and stored individually in $1.5 \mathrm{ml}$ Eppendorf tubes containing cotton-lined silica gel at $-20^{\circ} \mathrm{C}$ for molecular identification of An. gambiae complex members and detection of the Kdr mutation.

\section{Molecular identification of An. gambiae complex species}

Genomic DNA from mosquitoes was extracted following a procedure using $2 \% \mathrm{CTAB}$ as grinding buffer [22]. The species of the An. gambiae s.l. complex were identified by SINE 200 PCR [23]. The search for the Kdr mutation in insecticide-resistant Anopheles samples was done according to the procedure of [24].

\section{Results}

\section{Identification and spatial distribution of An. gambiae species in the study sites}

A total of 431 mosquitoes had their genomic DNA extracted for molecular identification of An. gambiae complex species. The populations of An. gambiae s.l. at both study sites were composed of An. coluzzii and An. gambiae. In Akoun, from the 218 mosquitoes identified, An. gambiae represented $9.17 \%$ and An. coluzzii $90.83 \%$. In Ebabodo, from the 213 mosquitoes analysed, $76.69 \%$ belonged to the species An. coluzzii and $20.31 \%$ to An. gambiae (Figure 2). An. coluzzii was significantly more represented than An. gambiae in both sites $(\mathrm{p} \leq .10-4)$.

\section{Insecticide susceptibility testing}

A total of 720 female An. gambiae s.l. mosquitoes aged 2 to 4 days were subjected to three insecticides (DDT $4 \%$, Permethrin $0.75 \%$ and Deltamethrin 0.05\%). 240 mosquitoes from Ebabodo; 240 mosquitoes from Akoun and 240 mosquitoes of the control strain of An. gambiae.

\section{Knock-down times (tkd50 and tkd95)}

For An. gambiae s.l. from both Akoun and Ebabodo, both tkd50

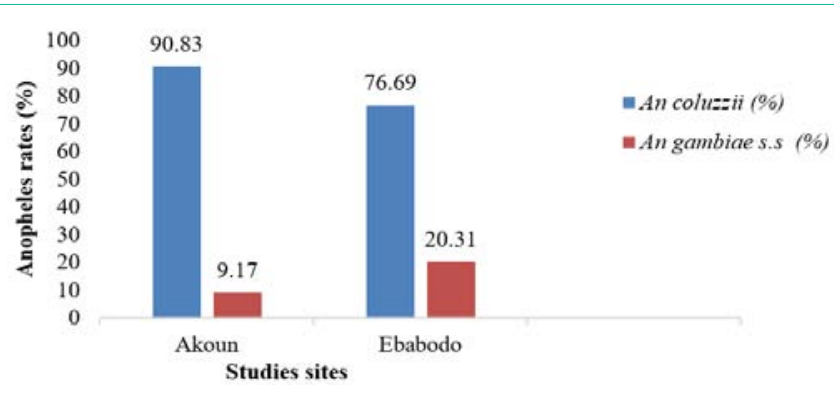

Figure 2: Distribution of An. gambiae complex species according to collection sites.

Table 1: An. gambiae s.l. knockdown times to insecticides.

\begin{tabular}{|c|c|c|c|c|}
\hline \multirow{2}{*}{ Strains } & Insecticide & $\mathbf{N}$ & $\mathbf{t k d}_{\mathbf{5 0}}(\mathbf{m i n})\left[\mathbf{C l}_{95}\right]$ & $\mathbf{t k d}_{95}(\mathbf{m i n})\left[\mathbf{C l}_{95}\right]$ \\
\hline \multirow{3}{*}{ Akoun } & DDT 4\% & 80 & $>60$ & $>60$ \\
\cline { 2 - 5 } & Perm. $0.75 \%$ & 80 & $>60$ & $>60$ \\
\cline { 2 - 5 } & Delta. $0.05 \%$ & 80 & $>60$ & $>60$ \\
\hline \multirow{3}{*}{ Ebabodo } & DDT 4\% & 80 & $>60$ & $>60$ \\
\cline { 2 - 5 } & Perm. $0.75 \%$ & 80 & $>60$ & $>60$ \\
\cline { 2 - 5 } & Delta. $0.05 \%$ & 80 & $>60$ & $>60$ \\
\hline \multirow{3}{*}{ Kisumu } & DDT 4\% & 80 & $19.1(17.8-21.1)$ & $31.2(28.2-33.4)$ \\
\cline { 2 - 5 } & Perm. $0.75 \%$ & 80 & $9.5(8.4-10.8)$ & $17.3(15.7-19.4)$ \\
\cline { 2 - 5 } & Delta. $0.05 \%$ & 80 & $8.8(7.3-11.1)$ & $14.0(12.6-17.8)$ \\
\hline
\end{tabular}

N: Number Tested; 95: Cl: 95\% Confidence Interval; min: Minute; Delta: Deltamethrin; Perm: Permethrin; tkd50: Time to Stun 50\% of Mosquitoes; tkd95: Time to Stun $95 \%$ of Mosquitoes.

Table 2: Mortality of An. gambiae s.l. females after 24 hours observation in Akoun and Ebabodo.

\begin{tabular}{|c|c|c|c|c|c|}
\hline \multirow{3}{*}{ Strain } & Insecticide & N & \% mortality & Controls & Statuts \\
\hline \multirow{3}{*}{ Akoun } & Perm. 0.75\% & 80 & $22.50 \%$ & 0 & Resist. \\
\cline { 2 - 6 } & Delta. 0.05\% & 80 & $12.50 \%$ & 0 & Resist. \\
\cline { 2 - 6 } & DDT. 4\% & 80 & $2.70 \%$ & 0 & Resist. \\
\hline \multirow{3}{*}{ Ebabodo } & Perm. 0.75\% & 80 & $10 \%$ & 0 & Resist. \\
\cline { 2 - 6 } & Delta. 0.05\% & 80 & $22.50 \%$ & 0 & Resist. \\
\cline { 2 - 6 } & DDT. 4\% & 80 & $7.50 \%$ & 0 & Resist. \\
\hline \multirow{3}{*}{ Kisumu } & Perm. 0.75\% & 80 & $98 \%$ & 0 & Sensib. \\
\cline { 2 - 6 } & Delta. 0.05\% & 80 & $100 \%$ & 0 & Sensib. \\
\cline { 2 - 6 } & DDT. 4\% & 80 & $100 \%$ & 0 & Sensib. \\
\hline
\end{tabular}

N: Number Tested; Delta: Deltamethrin; Perm: Permethrin; \% Dead: Percentage of Mortality; Resist: Resistant.

and tkd95 were above 1 hour with permethrin, deltamethrin and DDT. For An. gambiae (Kisumu strain), the tkd50 was $19.1 \mathrm{~min}$ with DDT, $9.5 \mathrm{~min}$ with permethrin and $8.8 \mathrm{~min}$ with deltamethrin. In addition, the tkd95 was $31 \mathrm{~min}$ with DDT, $17.3 \mathrm{~min}$ with Permethrin and $14 \mathrm{~min}$ with Deltamethrin (Table 1).

\section{Mortality rates of adult females of Anopheles gambiae s.I.}

In Akoun, the mortality rates recorded 24 hours after exposure to discriminating doses of the three insecticides were $22.5 \%, 12.5 \%$ and $2.7 \%$ respectively for permethrin, deltamethrin and DDT (Table 2). In Ebabodo, the mortality rates resulting from exposure to discriminating doses of the three insecticides were $10 \%, 22.5 \%$ and $7.5 \%$ for permethrin, deltamethrin and DDT respectively (Table 2). 
Table 3: Comparison of mean mortalities of An. gambiae s.l. populations in Akoun and Ebabodo subjected to insecticides (Kruskal Wallis $\mathrm{H}$-test, $\mathrm{P}<0.05$ ).

\begin{tabular}{|c|c|c|c|c|}
\hline \multirow{2}{*}{ Tested insecticides } & \multicolumn{2}{|c|}{ Strains } & \multirow{2}{*}{ H } & \multirow{2}{*}{ P } \\
\cline { 2 - 4 } & Akoun & Ebabodo & & \\
\hline DDT (4\%) & $0.5 \pm 0.50^{*}$ & $1.5 \pm 1.2$ & 17.40 & 0.15 \\
\hline Perm. (0.75\%) & $4.5 \pm 2.08$ & $2 \pm 1.6$ & 1.54 & 0.21 \\
\hline Delta. (0.05\%) & $2.5 \pm 2.3$ & $4.5 \pm 1.29$ & 5.07 & 0.3 \\
\hline${ }^{*} \mathrm{X} \pm$ Standard Deviation. & & & & \\
\hline
\end{tabular}

Table 4: Allele frequencies of Kdr mutations in An. gambiae s.I.

\begin{tabular}{|c|c|c|c|}
\hline & \multicolumn{3}{|c|}{ Allele frequencies } \\
\hline Sites & $\mathrm{N}$ & $\mathrm{R}$ & $\mathrm{S}$ \\
\hline Akoun & 100 & 1 & 0 \\
\hline Ebabodo & 100 & 1 & 0 \\
\hline Total & 100 & 1 & 0 \\
\hline
\end{tabular}

S: Susceptible kdr Allele; R: Resistant Allele; N: Number of Tested Individuals.

The comparative study of mortality rates between the native populations of An. gambiae s. 1. in Akoun and those in Ebabodo revealed that there was no significant difference between the mean mortality of $A n$. gambiae s. 1. from the two study sites irrespective of the insecticides tested $(\mathrm{P}>0.05)$ (Table 3$)$.

\section{Distribution of the Kdr mutation}

The frequency of the Kdr mutation was very high in both study sites. All An. gambiae s.l. specimens tested carried the (R) allele for an allelic frequency of 1 at locus 1014 while the (S) allele was absent at the same locus (Table 4).

\section{Discussion}

The present study revealed two species of the Anopheles gambiae s.l. complex in Akoun and Ebabodo. These are An. gambiae and An. coluzzii. Our results corroborate those recorded in the city of Douala in Cameroon $[9,25,26]$. These two species are known to be the most important malaria vectors in tropical Africa [27,28]. The results further show a predominance of $A n$. coluzzii in our study sites. This predominance of An. coluzzii in the locality of Ebabodo (periurban area) and Akoun (urban area) could be explained by the high ecological plasticity of this species compared to An. gambiae which prefers sunny natural sites with low conductivity and salinity values [29,30]. Similar results were found in Manoka by Talipouo et al. [31].

The present study revealed a wide distribution of resistance of $A n$. gambiae s.l. to DDT $4 \%$, permethrin $0.75 \%$ and deltamethrin $0.05 \%$ in the study sites. This resistance is reflected by an increase in knockdown time of natural populations compared to the sensitive reference strain, suggesting a mutation-induced structural modification of the sodium-dependent canal and thus a decrease in the affinity of all three insecticides used towards the target. Indeed, the massive use of insecticides in agriculture in secondary cities and in public health is the cause of selective pressures leading to the selection of insecticide resistance in malaria vectors $[29,30,32,33]$. In addition, other factors such as the regular use of insecticide bombs by the population and urban pollution are also present [9]. The tkds values achieved in this study are significantly higher than those previously obtained in the city of Douala by Antonio-Nkondjio et al. (2011) [9] and Akono et al. [26] respectively. This result suggests the evolving resistance of mosquitoes to insecticides in secondary cities.
In Central Africa, previous work has revealed a predominance of the Kdr West 1014F mutation [34,35]. In our study sites, the level of resistance to DDT and pyrethroids has increased significantly in the entire An. gambiae s.l. population and is correlated with the presence of the $1014 \mathrm{~F}$ mutation. Although Akoun is more urbanised than Ebabodo, the Kdr allele frequency was present in both sites. These allelic frequencies observed in our study are higher than those reported by Antonio et al. [30] in the city of Douala and suggest a trend towards fixation of the Kdr allele in Cameroonian Anopheles populations. This result reflects the global increase in pyrethroid resistance in malaria vectors in Africa [36]. However, no significant differences were observed according to ecological context. In both sites, the Kdr allele frequency was high and almost fixed in An. gambiae and An. coluzzii. This result could be explained by a continuous process of $\mathrm{Kdr}$ allele dissemination in the An. gambiae population in Cameroon [32]. It is suspected that the use of insecticides in agriculture or domestic hygiene as well as the use of impregnated mosquito nets in the southern region of Cameroon has led to the selection of the $\mathrm{Kdr}$ allele within the vectors. Indeed, the massive use of DDT during the 1960s-1970s for malaria control is suspected to be responsible for the resistance in Anopheles species [37]. The high proportions of RR genotypes in the survivors of the three insecticides seem to suggest that these provide a selective advantage in the two Anopheles species under selection pressure. In addition, other resistance mechanisms such as increased activity of detoxification systems and Acel may add to the Kdr effect and increase resistance to DDT and pyrethroids.

\section{Acknowledgment}

We thank the entire population of Ayos health district, the OCEAC (Organization de la coordination pour la lutte contre les endémies en Afrique Centrale) for their collaboration.

\section{References}

1. Gérard M. Paludisme: un vaccin qui surprend. Sci. Vie. 1993; 908: 29-30.

2. World Health Organization. World malaria report 2020: 20 years of global progress and challenges. In World malaria report 2020: 20 years of global progress and challenges. 2020: 300 .

3. World Health Organization. Global technical strategy for malaria 20162030. World Health Organization. WHO/HTM/GMP/2015.2). World Health Organization. 2015: 16.

4. Townson $\mathrm{H}$, Nathan $\mathrm{MB}$, Zaim M, Guillet $\mathrm{P}$, Manga L, Bos R, et al. Exploiting the potential of vector control for disease prevention. Bull. WHO. 2005; 83: 942-947.

5. Minsante. Rapport final d'enquête post campagne sur l'utilisation des moustiquaires imprégnées d'insecticides à longue durée d'action. 2017: 120.

6. PNLP. Plan Strategique National de lutte contre le Paludisme au Cameroun 2019-2023. 2019: 103.

7. Chouaïbou M, Etang J, Brevault T, Nwane P, Hinzoumbé CK, Mimpfoundi $\mathrm{R}$, et al. Dynamics of insecticide resistance in the malaria vector Anopheles gambiae s.l from an area of extensive cotton cultivation in Northern Cameroon. Trop. Med. Int. Health. 2008; 13: 1-11.

8. Nwane P, Etang J, Chouaïbou M, Toto JC, Mimpfoundi R, Simard F. Kdrbased insecticide resistance in Anopheles gambiae s.s populations in Cameroon: spread of the L1014F and L1014S mutations. BMC. Res. Notes. 2011; 4: 1-9.

9. Antonio-Nkondjio C, Fossog BT, Ndo C, Djantio BM, Togouet SZ, AwonoAmbene $\mathrm{P}$, et al. Anopheles gambiae distribution and insecticide resistance in the cities of Douala and Yaoundé (Cameroon): influence of urban agriculture and pollution. Malar J. 2011; 10: 1-13. 
10. Akono NP, Mbida Mbida JA, Tonga CA, Yomon K, Youmbi L, Lehman LG. Données préliminaires sur le paludisme humain en zones rurale et sémiurbaine du département du Nkam (Littoral-Cameroun). J. Appl. Biosci. 2017; 115: 11441-11452.

11. Wondji C, Simard F, Petrarca V, Etang J, Santolamazza F, Della Torré A, et al. Species and populations of the Anopheles gambiae complex in Cameroon with special emphasis on chromosomal and molecular forms of Anopheles gambiae s.s. J. Med. Entomol. 2005; 42: 998-1005

12. Pages F, Orlandi-Pradines E, Corbel V. Vecteurs du paludisme: biologie diversité, contrôle et protection individuelle. Med. Mal. Infect. 2007; 37: 153 161

13. Mbida Mbida A, Akono NP, Awono-Ambene P, Tchoffo R, Talipouo A, Ekoko $W$, et al. Insecticidal nets versus kdr-resistant mosquitoes. Curr. Trends Entomol Zool Stds. 2018; 106: 1-10.

14. Ntoumba AA, Foko LPK, Ekoko WE, Ndongo JM, Bunda GW, Meva FEA, et al. Entomological characteristics of mosquitoes breeding sites in two areas of the town of Douala, Cameroon. Int. J. Trop. Insect. Sci. 2021; 41: 1313-1323.

15. Akono NP, Tonga C, Kekeunou S, Lehman LG. Mosquito species diversity and malaria transmission in Ayos, an area of degraded forest targeted for universal LLIN distribution in southern Cameroon. Afr. Entomol. 2014; 22 : 602-610.

16. Service MW. Mosquito Ecology: Field Sampling Methods. $2^{\text {nd }}$ Edition Chapman \& Hall, London, UK. 1993: 700.

17. Desfontaines MA, Tchikangwa I, Le goff G, Robert V. Influence de l'alimentationdes larves d'Anopheles gambiae. (Dipera, Culicidae) sur le développement préimaginal en insectarium. Yaoundé: OCEAC. 1991: 7.

18. Gillies MT, Coetzee MA. Supplement to the Anophelinae of Africa South of the Sahara. $2^{\text {nd }}$ edn. Publ. South. Afri. Inst. Med. Res. 1987; 55: 1-143.

19. Gillies MT, De Meillon D. The Anophelinae of Africa South of the Sahara Publ. South. Afri. Inst. Med. Res. 1968; 54: 1-343.

20. World Health Organization. Test procedures for insecticide resistance monitoring in malaria vectors. WHO. Geneva. 2013.

21. Abbot WS. A method of computing the effectiveness of an insecticide. J. Am Mosq. Control Assoc. 1987; 3: 302-303

22. Myriam and Cécile. Extraction d'AND au CTAB sur moustique entier. 2003.

23. Santolamazza F, Mancini E, Simard F, Qi Y, Tu Z, Della Torre A. Insertion polymorphisms of SINE200 retrotransposons within speciation islands of Anopheles gambiae molecular forms. Malar. J. 2008; 7: 1-10.

24. Martinez-Torres D, Chandre F, Williamson MS, Darriet F, Bergé JB, Devonshire AL, et al. Molecular characterization of pyrethroid knockdown resistance (kdr) in the major malaria vector Anopheles gambiae s.s. Insect. Mol. Biol. 1998; 7: 179-184.

25. Kamdem C, Tene Fossog B, Simard F, Etouna J, Ndo C, Kengne P, et al. Anthropogenic Habitat Disturbance and Ecological Divergence between Incipient Species of the Malaria Mosquito Anopheles gambiae. PLoS ONE. 2012; 7: 439-453.
26. Akono NP, Tonga C, Mbida Mbida JA, Ngo Hondt OE, Awono Ambene $\mathrm{P}$, Ndo C, et al. Anopheles gambiae, vecteur majeur du paludisme à Logbessou, zone péri-urbaine de Douala (Cameroun). Bull. Soc. Pathol. Exot. 2015; 108: 360-368

27. Coz J. Contribution à l'étude du complexe A. gambiae. Répartition géographique et saisonnière en Afrique de l'Ouest. Cah. O.R.S.T.O.M. Ser Ent. méd. et Parasitol. 1973; 11: 3-31.

28. Coetzee M, Hunt RH, Wilkerson R, Della Torre A, Coulibaly MB, Besansky NJ. Anopheles coluzzii and Anopheles amharicus, new members of the Anopheles gambiae complex. Zootaxa. 2013; 3619: 246-274.

29. Etang J, Fondjo E, Chandre F, Morlais I, Brengues C, Nwane P, et al. Short report: first report of knockdown mutations in the malaria vector anopheles gambiae from cameroon. Am. J. Trop. Med. Hyg. 2006; 74: 795-797.

30. Antonio-Nkondjio C, Fossog BT, Kopya E, Poumachu Y, Djantio BM, Ndo $\mathrm{C}$, et al. Rapid evolution of pyrethroid resistance prevalence in Anopheles gambiae populations from the cities of Douala and Yaoundé (Cameroon). Malar. J. 2015; 14: 1-9

31. Talipouo A, Akono NP, Tagne D, Mbida Mbida A, Etang J, Tchoffo FR, et al. Comparative study of Culicidae biodiversity of Manoka island and Youpwe mainland area, Littoral, Cameroon. Int. J. Biosci. 2017; 10: 9-18.

32. Etang J, Manga L, Toto JC, Guillet P, Fondjo E, Chandre F. Spectrum of metabolic-based resistance to DDT and pyrethroids in Anopheles gambiae s.I. populations from Cameroon. J. Vector. Ecol. 2002; 32: 123-133.

33. Nwane P, Etang J, Chouaibou M, Toto J, Kerah-Hinzoumbe C, Mimpfoundi R. Trends in DDT and pyrethroid resistance in Anopheles gambiae s.s. Populations from urban and agro-industrial settings in southern Cameroon. BMC. Infect. Dis. 2009; 9: 1-10.

34. Pinto J, Lynd A, Elissa N, Donnelly MJ, Costa C, Gentile G, et al. Cooccurrence of East and West African kdr mutations suggests high levels of resistance to pyrethroid insecticides in Anopheles gambiae from Libreville, Gabon. Med. Vet. 2006; 20: 27-32.

35. Reimer L, Fondjo E, Patchoké S, Diallo B, Lee Y, Arash NG, et al. Relationship between kdr mutation and resistance to pyrethroid and DDT insecticides in natural populations of Anopheles gambiae. J. Med. Entomol. 2008; 45: 260266.

36. Ranson $H$, Jensen B, Vulvule JM, Wang X, Hemingway J, Collins FH. Identification of a point mutation in the voltage-gated sodium channel gene of Kenyan Anopheles gambiae associated with resistance to DDT and pyrethroids. Insect. Mol. Biol. 2000; 9: 491-497.

37. Akogbéto M, Yakoubou S. Resistance of malaria vectors to pyrethroids used for impregnated bednets, Benin, West Africa. Bull. Soc. Path. Exot. 1999; 92: 123-130. 